\title{
Clonorchis sinensis
}

National Cancer Institute

\section{Source}

National Cancer Institute. Clonorchis sinensis. NCI Thesaurus. Code C122262.

A species of liver fluke in the class T rematoda. The life cycle of $C$. sinensis involves

freshwater snails, fish, and humans. In humans they are found mainly in the common bile duct and gall bladder where they feed on bile. 